\title{
Educação Ambiental nas Escolas Rurais do município de Piracanjuba/Goiás - Brasil
}

\author{
Educación Ambiental en las Esculas Rurales de Piracanjuba/Goiás - \\ Brasil
}
Environmental Education on the Rural Schools of Piracanjuba/Goiás - Brazil

\author{
Natali Aristizabal Lancheros ${ }^{1}$ \\ Flávio Reis dos Santos²
}

\begin{abstract}
Resumo
É preciso compreender a importância e transcendência da implementação da Educação Ambiental (E.A.) nas escolas rurais, como ferramenta dinâmica para a emancipação das comunidades, onde se trabalham aspectos fundamentais como o empoderamento territorial, político-econômico e social, junto com enraizamento e reconexão das tradições e a cultura, na perspectiva de ter uma vida digna e sustentável ecologicamente. $\mathrm{O}$ objetivo deste estudo é averiguar a existência da prática de políticas públicas de E.A. e a aplicação das Diretrizes Curriculares propostas pelo Ministério de Educação, no Ensino Fundamental I, nas escolas municipais rurais de Piracanjuba/Goiás - Brasil. Opta-se por uma metodologia a qual retoma aspetos da Investigação-AçãoParticipação (I.A.P.), já que esta constitui recurso importante para a compreensão do papel científico-social na tarefa de contribuir para diminuir as injustiças socioeconômicas, assim como, por sua possibilidade de gerar consciência sociopolítica entre os sujeitos participantes do processo. Ao estudar a história da educação brasileira, se percebe que a educação no meio rural tem sido tratada pelo poder público como política compensatória, não considerando o contexto em que as escolas estão inseridas, com suas relações sociais, ecológicas, políticas, culturais e territoriais. A pesquisa encontra-se em processo de investigação de campo (diagnóstica); mas tem-se observado significativa quantidade de problemáticas, não somente em relação à implementação da política pública e diretrizes curriculares da E.A., mas também outras, fiéis representantes à negação e negligência dos entes públicos ante ao direito de uma educação digna, de qualidade e coerente com a realidade, para as populações rurais.
\end{abstract}

Palavras-Chave: Educação Ambiental; Educação Rural; Políticas Públicas.

\section{Resumen}

\footnotetext{
${ }^{1}$ Mestranda do Programa de Pós-Graduação em Ambiente e Sociedade da Universidade Estadual de Goiás (PPGAS/UEG); Brasil. nataliajuro@hotmail.com. Trabalho apresentado no I Seminário Latino-Americano de Estudos em Cultura SEMLACult, Foz do Iguaçu/PR, Brasil, 2017. Apoio financeiro da Universidade Estadual de Goiás (UEG), por meio do Programa de Auxilio Eventos (Pró-Eventos - Edital PrP nº 009/2017)

${ }^{2}$ Pós-Doutor em Educação Universidade Federal de São Carlos (UFSCar). Professor e Vice-Coordenador do Programa de Pós-Graduação Ambiente e Sociedade Universidade Estadual de Goiás (PPGAS/UEG) - reisdossantos.flavio@ gmail.com. Trabalho apresentado no I Seminário Latino-Americano de Estudos em Cultura - SEMLACult, Foz do Iguaçu/PR, Brasil, 2017.
} 
Es preciso comprende la importancia y trascendencia de la implementación de la Educación Ambiental (E.A.) en las escuelas rurales, como herramienta dinámica para la emancipación de las comunidades, donde se trabaje el empoderamiento territorial, político-económico e social, junto con el enraizamiento e reconexión de las tradiciones y la cultura, en la perspectiva de tener una vida digna e sustentable ecológicamente. El objetivo del estudio es averiguar la existencia de la práctica de las políticas públicas en E.A. y la aplicación de las Directrices Curriculares propuestas por el Ministerio del Educación, en los grados fundamental I de las escuelas municipales rurales de Piracanjuba/Goiás - Brasil. Se opta por una metodología que retoma aspectos de la Investigación Acción Participativa (I.A.P.), ya que constituye un recurso importante para la comprensión del papel científicosocial en la tarea de contribuir para la disminución de las injusticias socioeconómicas, así como, por su posibilidad de generar conciencia sociopolítica entre los sujetos participantes del proceso. Al estudiar la historia de la educación brasilera, se puede percibir que la educación en el medio rural ha sido tratada por el poder público como una política compensatoria, sin considerar el contexto en que las escuelas están inseridas, con sus realidades sociales, ecológicas, políticas, culturales y territoriales. La investigación está en etapa de campo (diagnóstica); pero se han observado una cantidad significante de problemáticas, no solamente en relación a la implementación de la política pública y directrices curriculares de la E.A; sino también de otras fieles representantes de la negación e negligencia de los entes públicos al derecho de una educación digna, de calidad y coherente con la realidad, para las comunidades rurales.

Palabras-Clave: Educación Ambiental; Educación Rural; Políticas Públicas.

\begin{abstract}
It is necessary to understand the importance and transcendence of the implementation of Environmental Education in rural schools, as a dynamic tool for the emancipation of communities, where the work is related to territorial, political-economic and social empowerment, along with rooting and reconnection of traditions and culture, in the perspective of having a dignified and ecologically sustainable life. The aim of study is to investigate the existence of the practice of public policies in Environmental Education, and the application of the Curricular Guidelines proposed by the Ministry of Education, in the fundamental grades I of the municipal rural schools of Piracanjuba / Goias - Brazil. It adopts a methodology that takes up aspects of the ParticipatoryAction-Research (I.A.P), since it constitutes an important resource for the understanding of the scientific-social role in contributing to the reduction of socioeconomic injustices, as well as, to generate sociopolitical awareness among the subjects participants in the process. In the study of the history of Brazilian education, it is possible to perceive that the education in rural areas has been treated by the public power as a compensatory policy, without considering the context in which schools are inserted, with their social, ecological, political, cultural and territorial realities. The research is in the field stage (diagnostic); but a significant number of problems have been observed, not only in relation to the implementation of the public policy and curricular directives of the Environmental Education but also, other faithful representatives of the negation and negligence of the public entities to the right of have a decent, quality and coherent with the reality education; for the rural communities.
\end{abstract}

KeyWords: Environmental Education; Rural Education; Public Policies.

\title{
1. Introdução
}

Reconhecer as mudanças paradigmáticas na conscientização e reconexão dos estudantes no que diz respeito à Educação Ambiental nas escolas rurais no Brasil, está articulada ao reconhecimento da luta pela Educação Rural (ER) ${ }^{3}$ de qualidade, inclusiva, diferenciada e coerente com os processos vividos pelas comunidades rurais, onde além de buscar as características para a Educação Ambiental Rural (EAR), deve se constituir em luta

\footnotetext{
${ }^{3}$ Esclarecimentos sobre Educação Rural, Educação do Campo e Educação no Campo consultar: SANTOS, Flávio Reis; BEZERRA NETO, Luiz. Educação no campo: história, desafios e perspectivas atuais. In: BASSO; Jaqueline Daniela; SANTOS NETO, José Leite; BEZERRA, Maria Cristina dos Santos. Pedagogia históricocrítica e educação no campo: história, desafios e perspectivas atuais. São Carlos/SP: Pedro \& João, 2016b.
} 
para o fortalecimento e construção de processos em prol dos direitos fundamentais das comunidades rurais caracterizadas historicamente pela submissão, marginalização e exclusão por parte de boa parte da sociedade e, sobretudo, pelo Estado.

Assim como a Educação do Campo (EC), a Educação Ambiental requer cada vez mais a atenção e preocupação do universo acadêmico, das comunidades locais e da sociedade em geral, resgatando sua importância socioambiental, política e cultural. Observamos que ainda são escassas as pesquisas que dizem respeito à implantação e verificação das políticas públicas, sobretudo, nas áreas rurais do Brasil. Portanto, entendemos que existe a necessidade de priorizar o empreendimento de tais investigações em o país, quer em nível municipal e estadual, quer em nível nacional.

Da compreensão da importância política, econômica, social, cultural e ecológica das políticas públicas para a Educação Ambiental, reiteramos, decorre a necessidade de verificar como estas estão sendo implementadas, bem como investigar se as Diretrizes Curriculares Nacionais para a Educação Ambiental (DCNEA) estão sendo praticadas nas escolas. Nesse contexto, vão-se retomar aspetos da investigação-ação-participativa para verificar a aplicação da legislação e outros aspectos votados ao institucionalização da E.A. em cinco escolas municipais rurais de Piracanjuba (termo indígena que significa peixe de cabeça amarela), localizadas na Bacia do Rio Paraná, no Estado de Goiás, situadas a 87 km da capital Goiânia. O município se estende por $2.405 \mathrm{~km}^{2}$, numa altitude de 740 metros com clima tropical e suas coordenadas geográficas são as seguintes: Latitude $17^{\circ} 17^{\prime} 47^{\prime \prime}$ Sul e Longitude $49^{\circ} 0^{\prime} 38^{\prime \prime}$ Oeste (IBGE, 2016; PIRACANJUBA, 2016).

A viabilização e implantação das políticas públicas em Educação Ambiental, articuladas às DCNEA orientadas pelo Programa Nacional de Educação Ambiental (ProNEA) em prol dos processos de conscientização, reaprendizagem e reconexão das comunidades rurais são indispensáveis para a transformação dos paradigmas e realidades dos sujeitos, na perspectiva de melhorar seu futuro e qualidade de vida, imbricados às questões territoriais, políticas, econômicas, sociais, culturais, bem como aos processos de subsistência sustentáveis ecologicamente.

Nesse contexto, planteamos o objetivo de investigar a existência de ações voltadas para a Educação Ambiental nas escolas rurais do município de Piracanjuba alinhadas aos objetivos do Programa Nacional de Educação Ambiental do Ministério do Meio Ambiente (MMA). Além especificamente, vai-se identificar o conhecimento que os profissionais das escolas 
municipais rurais têm sobre o ProNEA e como a política de E.A. vem sendo implementada (ou não) no interior das unidades escolares, e assim mesmo examinar se as Diretrizes Curriculares Nacionais para a Educação Ambiental (DCNEA) são contempladas em seu currículo. Como objetivo final específico, vão-se discutir estratégias que ajudem a viabilizar a E.A. em conformidade com Programa Nacional de Educação Ambiental e com as Diretrizes Curriculares Nacionais.

\section{Metodologia}

Tomando em conta o objetivo, vai-se direcionar a pesquisa no marco do Ensino Fundamental I $\left(1^{\circ}\right.$ ao $\left.5^{\circ}\right)$ nas cinco escolas municipais rurais de Piracanjuba/Goiás - Brasil, a saber: Escola Municipal de Educação Básica José Marcelino de Lima (Povoado José Marcelino de Lima); Escola Municipal de Educação Básica Urbano Pedro Guimarães (Fazenda Areia); Escola Municipal de Educação Básica Serra Negra (GO 217 - km 17); Escola Municipal de Educação Básica Modesto Antonio de Paula (Fazenda Maiada); Escola Municipal de Educação Básica Sérgio Honorato Silva e Souza (BR 153 - km 568 Loteamento Dr. Rui Brasil).

Esclarecemos que a investigação conta a realização de três fases distintas: Formulação e Construção Teórica - revisão bibliográfica, contatos iniciais com os sujeitos da pesquisa e redefinição do projeto de pesquisa caso haja necessidade; Campo - Coleta de Dados: observação direita, realização diagnóstico, seleção sujeitos para as entrevistas, seleção sujeitos para os grupos focais, identificação das matrizes de problemas e análises de conflitos; Tabulação, Organização e Análise de Dados: organização informação por categorias de análises, sistematização da informação, triangulação dos resultados, análises e discussão de resultados por categorias.

Para realizar a pesquisa retomam-se algumas pautas da I.A.P. como metodologia; que propõe a interação entre os sujeitos comuns, para pôr o conhecimento sentimento-pensante a serviço dos interesses grupos submetidos e explorados pelos poder do capital, sobretudo, aqueles que vivem e trabalham no campo (FALS, 1987 apud CALDERON, CARDONA, 2010, p. 3).

Fals Borda, Bonilla e Castillo (1972) complementaram e criaram uma formulação, na qual o método estava: 
[...] baseado na inserção do investigador na comunidade a análise das condições históricas e a estrutura social da comunidade, o desenvolvimento do nível de consciência dos membros da comunidade, o desenvolvimento de organizações políticas e grupos de ação e o que eles chamaram de investigação militante, caracterizada por sua ênfase na solução de problemas e compromisso com a comunidade ou grupo[...]. (FALS, BONILLA, CASTILLO, 1985 apud BALCAZAR, 2003, p. 4$)^{4}$.

\section{Discussão}

Para contextualizar a pesquisa e as reflexões, é preciso ter uma perspectiva histórica do direito à educação, pois a educação é inerente ao desenvolvimento humano e é parte integrante e essencial da vida do homem em e na sociedade (LUZURIAGA, 1984 apud MOURA, 2014). Suas origens, reflexões e estruturação remontam tanto à Antiga Grécia como à Antiga Roma. Desde aquela época tem se vivenciado diferentes processos em todo o mundo, com diferentes histórias de lutas, fracassos, frustrações, conquistas até atingir um momento histórico recente, no qual o direito à educação tem origem jurídica, com força de lei, a partir da Declaração Universal dos Direitos Humanos: “Artigo 26: Toda pessoa tem direito à educação. A educação deve ser gratuita, pelo menos no concernente à instrução elementar e fundamental. A instrução elementar será obrigatória [...]”(UNESCO, 2013, p. 17) .

Na mesma direção temos a Convenção dos Direitos da Criança de 1989, que reitera o ordenamento equivalente ao Pacto de 1966, relacionado com a acessibilidade, gratuidade e obrigatoriedade dos diversos níveis educativos. Contudo, essa noção de escolaridade acessível, obrigatória e gratuita para a obtenção de um certificado de escolaridade é insuficiente (UNESCO, 2013).

De acordo com a Organização das Nações Unidas para a Educação, a Ciência e a Cultura (UNESCO), em documento intitulado "Situação Educativa de América Latina e o

\footnotetext{
4 “ [...] basado en la inserción del investigador en la comunidad, el análisis de las condiciones históricas y la estructura social de la comunidad, el desarrollo del nivel de conciencia de los miembros de la comunidad, el desarrollo de organizaciones políticas y grupos de acción y lo que ellos llamaron la investigación militante, caracterizada por su énfasis en la solución de problemas y el compromiso con la comunidad o grupo [...]" (FALS BORDA, 1985 apud BALCAZAR, 2003, p. 4).

5 "Toda persona tiene derecho a la educación. La educación debe ser gratuita, al menos en lo concerniente a la instrucción elemental y fundamental. La instrucción elemental será obligatoria [...]” (UNESCO, 2013).
} 
Caribe: Para uma Educação de Qualidade para Todos em 2015”, há uma troca na visão da suposta necessidade de assegurar uma educação de qualidade como direito fundamental: “[...] receber uma educação de qualidade deve ser visto como parte do direito à educação. A Convenção dos Direitos da Criança estabelece alguns critérios “permanentes" para definir o direito a aprender ou a receber uma educação de qualidade [...] (UNESCO, 2013, p. 18) ${ }^{7}$.

Além da ação e mediação da UNESCO, fazem parte desse processo, mediante a participação e intervenção, entidades como a Organização para a Cooperação e o Desenvolvimento Econômico (OCDE), Organização dos Estados Americanos (OEA), todas sob o financiamento do Banco Mundial (BM). A união destas instituições põe em prática todas as estratégias necessárias para o investimento na promoção do desenvolvimento econômico dos países capitalistas, sobretudo dos periféricos, em prol das grandes potências, "passando a integrar em caráter definitivo as agendas de governo das mais diversas nações do mundo, dominadas pelo racionalismo e eficiência tecnocrática, na determinação das políticas e administração da educação pública” (PIRES, 2005 apud SANTOS, 2015, p. 205).

Compreendemos que a criação, proclamação e administração da educação como direito fundamental por essas instituições e em uma educação para todos, incluindo as comunidades rurais, constitui uma via de mão dupla para os países periféricos do capitalismo e, portanto, o Brasil. Assim, direcionado pelos princípios tecnocráticos, justificado numa análise entre a relação custo e beneficio, e, priorizando as demandas do mercado e do saber como bem privado, as recomendações do Banco Mundial satisfazem as necessidade de ajuste (econômico e fiscal), dos países periféricos, sob interesses de países capitalistas (SANTOS, 2015). Entretanto, a existência e a materialização de todos esses processos implicam a obrigatoriedade dos governos e dos entes públicos para efetivar a sua execução.

Articulando as temáticas, faz-se pertinente ressaltar as lutas em defesa de educação de qualidade para os sujeitos que vivem no meio rural, iniciadas nos 1980 com o Movimento dos Trabalhadores Rurais Sem Terra (MST), especialmente, pela materialização da Primeira Conferência Nacional por uma Educação Básica do Campo - organizada pelo MST em

\footnotetext{
6 "Situación Educativa de América Latina y el Caribe: Hacia la educación de calidad para todos al 2015”.

7 “[...] recibir una educación de calidad debe ser visto como parte del derecho a la educación. La Convención de los Derechos del Niño y otros textos internacionales proporcionan tres criterios "permanentes" para definir el derecho a aprender o a recibir una educación de calidad [...]” (UNESCO, 2013, p. 18).
} 
conjunto com a Universidade de Brasília (UnB), Conferência Nacional dos Bispos do Brasil (CNBB), Organização das Nações Unidas para a Educação, a Ciência e a Cultura (UNESCO) e Fundo das Nações Unidas para a Infância (UNICEF), em Brasília, entre os dias 27 a 31 de julho de 1998, para a criação do Movimento Por Uma Educação do Campo (SANTOS, BEZERRA, 2016).

A partir dessa época surgiram vários movimentos que intensificaram a importância e demostraram a relevância da luta por uma educação que contribua para a liberdade nos processos de transformações paradigmáticas das realidades destes sujeitos em prol de uma melhor qualidade de vida garantindo os direitos fundamentais de suas comunidades (BEZERRA, 2010).

Tendo claro que a educação é a base e/ou a principal ferramenta das comunidades para sua emancipação, reiteramos que é preciso uma educação que esteja presente nas lutas sociais, e na conscientização e o fortalecimentos de conhecimentos e reconexão dos sujeitos tanto de seus territórios como de seus processos políticos, sociais, culturais e ecológicos. Incluir e compreender a história, as memórias, as lutas e fracassos, as tradições e culturas, reconstruindo a identidade e sua legitimidade; resgatando a importância da luta pela terra e todo o que os ecossistema constituem; é fundamental para assegurar o direito de uma vida digna com soberania e seguridade alimentar, ambiente saudável; todo isto junto com acesso e utilização das novas tecnologias que estejam associadas à sustentabilidade para a reconstrução de uma relação sustentação entre a comunidade e natureza. A vinculação de um conjunto de lutas pela transformação das condições sociais da vida no meio rural tem seu início, fundamentos no seio da educação (BEZERRA, 2010).

Portanto, a educação constitui a base para o desenvolvimento econômico, social, cultural e político de seus protagonistas e para construção de uma participação crítica e efetiva, para a incorporação de responsabilidades individuais e coletivas solidárias e satisfação das necessidades básicas dos sujeitos, tendo em vista o desenvolvimento do capital humano e social (BEZERRA, 2010).

Nesse sentido a Educação Ambiental torna-se fundamental para atingir os alvos de uma educação coerente, emancipadora e digna, com a anteriormente descrita, onde não podemos incorrer em o erro de concentrar a nossa apreensão da Educação Ambiental nos limites de um único conceito, pois estaríamos simplificando a sua dinâmica, complexidade, magnitude e importância na sociedade contemporânea. 
[...] a educação ambiental foi reduzida a um processo geral de conscientização cidadã, à incorporação de conteúdos ecológicos e ao fracionamento do saber ambiental a uma capacitação aligeirada sobre problemas pontuais, nos quais a complexidade do conceito de ambiente foi reduzido e mutilado (LEFF, 1999, p. 125).

A Conferência Intergovernamental de Tbilisi, capital da Geórgia em 1977, por sua vez, defende que a Educação Ambiental deve ser entendida como:

[...] um processo de reconhecimento de valores e clarificações de conceitos, objetivando o desenvolvimento das habilidades e modificando as atitudes em relação ao meio, para entender e apreciar as inter-relações entre os seres humanos, suas culturas e seus meios biofísicos (Conferência Intergovernamental de Tbilisi, 1977 apud BRASIL/MMA, 2016).

Michèle Sato e Carvalho (2005), de sua parte, argumentam que a E.A. constitui luta política, compreendida em seus aspectos mais efetivos de transformação, sendo:

[...] aquela que se revela em uma disputa de posições e proposições sobre o destino das sociedades, dos territórios e das desterritorializações; que acredita que mais do que conhecimento técnico-científico, o saber popular igualmente consegue proporcionar caminhos de participação para a sustentabilidade através da transição democrática (SATO; CARVALHO, 2005 apud BRASIL/MMA, 2016).

Além dessas definições, outras foram construídas no transcurso dos anos numa diversificação, adotando diferentes discursos e correntes de maneiras de conceber e de praticar a E.A. (FERRARO, 2007); este contexto nos leva a refletir que a " importância do entendimento da educação ambiental não deve se restringir a uma prática educativa singular ou como uma disciplina, mas como uma ciência complexa e multidisciplinar" (MELLO, TRAJBER, 2007, p. 104).

A Educação Ambiental crítica, vista como sinônimo de outras denominações, ou abordagens se caracteriza por ser uma prática social histórica que:

[...] necessita vincular os processos ecológicos aos sociais na leitura de mundo, na forma de intervir na realidade e de existir na natureza. [...] Além, reconhece que nos relacionamos por meio de dimensões que criamos na própria dinâmica de nossa espécie e que nos formam ao longo da vida (cultura, educação, classe social, instituições, família, gênero, etnia, nacionalidade etc.) (MELLO, TRAJBER, 2007, p. 64). 
Além da problemática marcada pela ausência de uma educação rural de qualidade, digna e reconhecida como direito fundamental dos indivíduos e das comunidades, a Educação Ambiental não é conhecida e/ou entendida desde a sua complexidade, interdisciplinaridade e sua capacidade de abarcar problemáticas ecológicas, econômicas, sociais, politicas, territoriais etc. Tem-se claro que a luta pelo reconhecimento e implementação, tanto da educação rural como da educação ambiental, coerente com a realidade dos sujeitos das comunidades, digna e que articule conhecimentos acadêmicos e populares e/ou tradicionais que direcionem a uma vida sustentável, é uma luta de todos e precisa ser visibilizada, compreendida e trabalhada em todas as esferas e âmbitos da sociedade.

\section{Conclusões}

Nossas investigações iniciais nos permitem afirmar que ao estudar a história da educação brasileira, podemos perceber que a educação rural e a educação ambiental têm sido tratadas pelo poder público com políticas compensatórias, não tendo em conta o contexto em que as escolas estão inseridas, com suas relações sociais, ecológicas, políticas, culturais e territoriais. "As políticas educacionais tratam a educação urbana como parâmetro a ser seguido e a rural como adaptação da primeira" (MELLO; TRAJBER, 2007, p. 63).

A desvalorização, a submissão, a marginalização e a invisibilidade das áreas rurais comparadas às áreas urbanas, ainda se fazem muito presentes nas mais diversas regiões de Latino América, como no Brasil; neste processo, emergem os movimentos populares e sociais, que lutam por uma educação de boa qualidade, especialmente, para as populações rurais ou do campo; estes movimentos estão ligados ao fortalecimento do empoderamento político, social, econômico e territorial. Portanto, faz-se necessária a compreensão da história, das memórias, das culturas e tradições dos sujeitos para que possamos reconstruir a sua identidade e legitimidade, resgatando a importância da luta pela terra e todos os serviços ecossistêmicos nela incluídos.

Reconhecendo que a crise atual resulta de um mesmo modelo de desenvolvimento capitalista que se afirma pela concentração econômica e exclusão social, pela degradação da natureza e do homem, que trazem consigo riscos socioambientais que fragilizam as instituições democráticas com padrões utilitário-individualistas (FERRARO, 2007).

Nesse sentido, entendemos que por meio da investigação das diversas instâncias e segmentos governamentais e privados, da pesquisa, da consciência e dos esforços acadêmicos, 
bem como da participação da sociedade em sentido amplo, orientada por uma Educação Ambiental consistente e efetiva, articulada pela luta por uma educação rural, que aponte os reais problemas enfrentados na atualidade e indique medidas e ações possíveis e executáveis para, pelo menos, amenizar a degradação do planeta e a exploração e marginalização de suas comunidades.

\section{Agradecimentos}

Queremos agradecer a o apoio financeiro dado pela Universidade Estadual de Goiás (UEG), por meio do Programa de Auxilio Eventos (Pró-Eventos - Edital PrP no 009/2017) para a apresentação do presente trabalho apresentado no I Seminário Latino-Americano de Estudos em Cultura - SEMLACult, Foz do Iguaçu/PR, Brasil, 2017.

\section{Referências}

BALCAZAR, F. Investigación acción participativa (IAP): aspectos conceptuales y dificultades de implementación. Fundamentos en Humanidades, v. 4, n. 7-8, p. 59-77, 2003. Disponível em: <http://www.redalyc.org/articulo.oa?id=18400804>. Acesso em: 28 jun. 2016.

BEZERRA N. L. Educação do campo ou educação no campo? Revista HISTEDBR, Campinas, n. 38, p. $150 \quad$ - 168, 2010. Disponível em: <http://www.histedbr.fe.unicamp.br/revista/edicoes/38/art12_38.pdf>. Acesso em: 8 dez. 2016.

BEZERRA, L; SANTOS, F. R. ESCOLAS ESTADUAIS EM ASSENTAMENTOS DAS ESCOLAS URBANAS: UMA COMPARAÇÃO A PARTIR DO SARESP. In: BASSO; J. D.; SANTOS, J. L; BEZERRA, M. C. Pedagogia histórico-crítica e educação no campo: história, desafios e perspectivas atuais. São Carlos/SP: Pedro \& João, 2016. p. 243 - 272. 
BRASIL. Diretrizes Curriculares Nacionais para a Educação Ambiental. Resolução CNE/CP 2/2012. Brasília/DF: Diário Oficial da União18 de junho de 2012.

BRASIL. Lei n. 6.938, de 31 de agosto de 1931. Dispõe sobre a Política Nacional do Meio Ambiente, seus fins e mecanismos de formulação e aplicação, e dá outras providências. Brasília: Presidência da República/Casa Civil, 1981. Disponível em: 〈http://www.planalto.gov.br/ccivil_03/leis/L6938.htm>. Acesso em: 3 jul. 2016.

BRASIL. Ministério do Meio Ambiente. Conceitos de educação ambiental. Brasília/DF: MMA, 2016. Disponível em: <http://www.mma.gov.br/educacao-ambiental/politica-deeducacao-ambiental>. Acesso em: 9 jul. 2016.

CALDERON, J.; CARDONA L. D. Orlando Fals Borda y la investigación acción participativa: aportes en el proceso de formación para la transformación. I Encuentro hacia una Pedagogía Emancipatoria en Nuestra América Publicación. Centro Cultural de la Cooperación Floreal Gorini. Ciudad de Buenos Aires. Disponível em: $<$ http://www.javeriana.edu.co/blogs/boviedo/files/pedagogc3adas-eman-lc3b3pez-cardona-ycalderc3b3n.pdf >. Acesso em: 12 jun. 2016.

FERRARO J. L. A. (Org.). Encontros e caminhos: formação de educadoras(es) ambientais e coletivos educadores. Volume 2. Brasília: MMA/DEA, 2007. Disponível em: <http://www.mma.gov.br/estruturas/educamb/_arquivos/encontros_2.pdf>. Acesso em: 16 jun. 2016.

INSTITUTO BRASILEIRO DE GEOGRAFIA E ESTATÍSTICA (IBGE). Cidades: Goiás/Piracanjuba. Disponível em: $<$ http://cidades.ibge.gov.br/xtras/perfil.php?lang=\&codmun=521710\&search=goias|piracanju ba>. Acesso em: 12 mar. 2016.

LEFF, E. Educação ambiental e desenvolvimento sustentável. In: REIGOTA, M. (org.). Verde cotidiano: o meio ambiente em discussão. Rio de Janeiro: DP\&A, 1999. 148 p.

MELLO, S. S.; TRAJBER, R. (Coord.). Vamos cuidar do Brasil: conceitos e práticas em educação ambiental na escola. Brasília/DF: MEC/MMA/UNESCO, 2007. Disponível em: <http://portal.mec.gov.br/dmdocuments/publicacao3.pdf>. Acesso em: 8 jul. 2016.

MOURA, Romilso Mizael. Uma leitura hitórico-contextual da escola de tempo integral. p. 102f; 2014 . Dissertação (Doutorado em Educação) - Universidade Metodista de Piracicaba/SP; 2010.

PIRACANJUBA (Goiás - Brasil). Portal Prefeitura Municipal. História da cidade. Disponível em: <http://www.piracanjuba.go.gov.br/site/historia.html. Acesso em: 19 jul. 2016. 
SANTOS, F. R. Capitalismo, Tecnocracia e Educação: da Utopia Social Saintsimoniana à Economia Neoliberal Friedmaniana. Jundiaí / SP: Paco Editorial, 2015. 282 p.

SANTOS, F. R. Políticas públicas de educação no/do campo: o transporte de estudantes no município de Morrinhos/Goiás. 2016. 128f. Relatório (Estágio Pós-Doutoral em Educação) Universidade Federal de São Carlos, São Carlos/SP, 2016.

SANTOS, F. R.; BEZERRA, L. Educação no campo: história, desafios e perspectivas atuais. In: BASSO, J. D.; SANTOS N. J. L.; BEZERRA, M. C. Pedagogia histórico-crítica e educação no campo: história, desafios e perspectivas atuais. São Carlos/SP: Pedro \& João, 2016.

SANTOS, F. R.; BEZERRA, L. Políticas públicas para a educação rural: da ausência à regulamentação do Programa Nacional de Reforma Agrária. In: SANTOS, F. R.; ROTHEN, J. C. (Orgs.). Políticas públicas para a educação no Brasil: entre avanços e retrocessos. São Carlos: PIXEL, 2016.

UNESCO. Conferência Nacional Por Uma Educação Básica do Campo (CNBC). Brasília/DF: MST/UNB/CNBB/UNICEF/UNESCO, jul. 1998. Disponível em: <http://unesdoc.unesco.org/images/0014/001497/149798porb.pdf>. Acesso em: 2 jul. 2016.

UNESCO. Situación Educativa de América Latina y el Caribe: Hacia la educación de calidad para todos al 2015. Regional de Educación para América Latina y el Caribe (OREALC/UNESCO), 2013; p. 209. Disponível em: $<$ http://www.unesco.org/new/fileadmin/MULTIMEDIA/FIELD/Santiago/images/SITIEDespanol.pdf $>$. Acesso em: 2 jul. 2016. 